\title{
Preparation and Characterization of Molybdenum Thin Films by Direct-Current Magnetron Sputtering
}

\author{
Shih-Fan Chen', Shea-Jue Wang ${ }^{1 *}$, Win-Der Lee ${ }^{2}$, Ming-Hong Chen', Chao-Nan Wei', and \\ Huy-Yun Y. Bor ${ }^{3}$
}

'Department of Materials and Minerals Resources Engineering, National Taipei University of Technology, Taipei 106, Taiwan; ${ }^{2}$ Department of Electrical Engineering, Lee-Ming Institute of Technology, New Taipei City 24305, Taiwan; ${ }^{3}$ Materials \& Electro-Optics Research Division, Chung-Shan Institute of Science \& Technology, Taoyuan 325, Taiwan.

Received: December 7, 2014 / Accepted: March 15, 2015

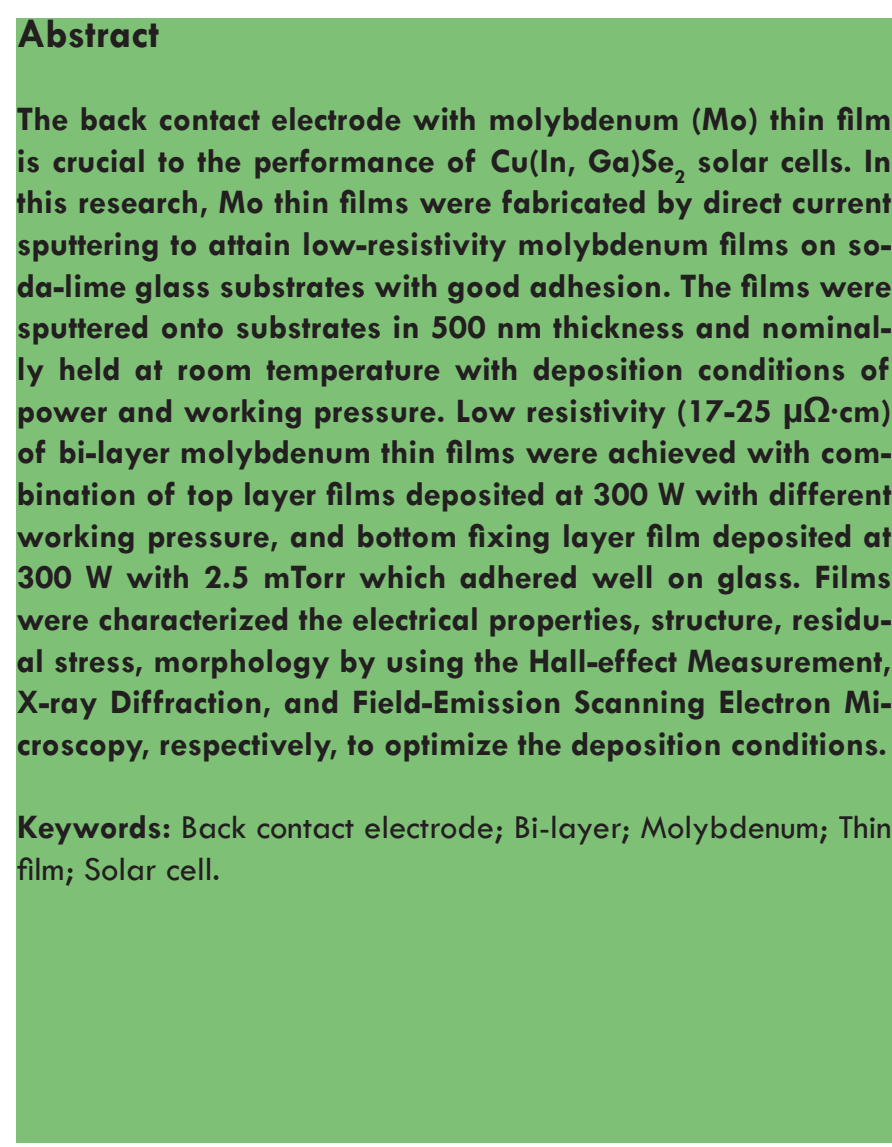

*Corresponding author: sjwang@ntut.edu.tw

\section{Introduction}

Solar cells are one of the important alternative energy technologies to alleviate the demands on the fossil and nuclear energy (Dresselhaus et al. 2001). The solar cells fabricated with various thin film materials on the substrate, such as the glass, metal foil or plastic with cheap production offer potential applications in our daily life technologies. The thin film solar cells may be classified as cadmium telluride, copper indium gallium diselenide, amorphous and polycrystalline silicon, organics, polymer and dye sensitive materials (Green et al. 2011).

From all current solar cell technologies, the one with more industrial interest and the capability of producing gigawatt per year is $\mathrm{Cu}(\mathrm{In}, \mathrm{Ga}) \mathrm{Se} 2$ (CIGS) based solar cells (Dhere 2007). Remarkable progress has been made in the development of conversion efficiency of CIGS cells on glass substrates that is beyond $20 \%$ (Jackson et al. 2011 ). However, transferring CIGS PV modules from lab to manufacturing scale has been much more challenging for the requirements of higher module efficiency, columnar CIGS structures deposited by robust process for high efficiency cells and modules, thinner absorber layer $(\leq 1 \mu \mathrm{m})$, and CIGS absorber film stoichiometry and uniformity over large areas, refer to the paper by Singh et al. (2010).

The device structure of CIGS cell comprises of a substrate, metal back contact layer, CIGS (absorber layer), CdS (buffer layer), $\mathrm{ZnO}$, and $\mathrm{Al} 2 \mathrm{O} 3$-doped $\mathrm{ZnO}$ (window layer), in which each layer has significant effects on the cell performance (Wu et al. 2012). The resistivity of back contact can affect the series resistance of the cell circuit to deteriorate the fill factor of solar cell. The other beneficial factors for back contact layer in CIGS A Prthns
This is an Open Access article distributed under the terms of the Creative Commons Attribution License (http://creativecommons.org/licenses/by/3.0/), which permits unrestricted use, distribution, and reproduction in any medium, provided the original work is properly cited. 
cell require good adhesion, smooth roughness, chemically inert with the materials deposited on top and high reflectivity of film on substrate (Jubault et al., 2011). Moreover, the back contact layer serves as a diffusion barrier hindering the diffusion of impurities from the substrate into the absorber (Yoon et al., 2011). Molybdenum (Mo) is a metal widely used as a back contact for CIGS solar cells, which can be deposited as thin films with a good resistivity, a good adhesion and fair smoothness. It does not react with $\mathrm{Cu}, \mathrm{Ga}$ or $\mathrm{In}$. A MoSe2 layer was formed during the CIGS process to minimize the negative effect of Schottky barrier at the CIGS/Mo interface and enhance the ohmic contact behavior on solar-cell performances (Hsiao et al. 2013). With 0.1 at. $\% \mathrm{Na}$ incorporated into the CIGS absorber layer, the performance of CIGS solar cells using soda-lime glass (SLG) substrates can be improved. The Mo films allow the diffusion of Na from the SLG during CIGS growth process.

Mo films on CIGS have been synthesized using sputter deposition (Huang et al. 2013; Wang et al. 2014), e-gun evaporation (Hoffman et al. 1991). However, most of research works take the sputtering method as the major deposition way for the target of refractory metal with high melting temperatures and large area process. In addition, controlling gas atmosphere and substrate temperature for the quality of films is more feasible than for other deposition techniques. In this work, we systematically investigated the influence of deposition parameters such as the direct current (DC) power and working gas pressure on structural, morphological, and electrical properties of molybdenum films. With through understanding the single layer of Mo films on SLG, bilayer Mo film on SLG were studied to explore the feasible conditions of stacked films for CIGS solar cell.

\section{Experimental Procedure}

The Mo films were deposited onto SLG substrates (EAGLE 2000, Corning Incorporated) by the DC magnetron sputtering of a high-purity molybdenum target (3 inch in diameter, $99.99 \%$; KaoDuen Technology Corp., Taiwan) in a vacuum chamber with a base pressure $<7 \times 10^{-6}$ Torr. Pure argon (99.99\%) was used as sputtering gas to deposit the Mo films. The working distance between target and substrate is $9 \mathrm{~cm}$. Before the deposition, the glass substrate with a dimension of $2.54 \mathrm{~mm} \times 2.54 \mathrm{~mm} \times$ $0.7 \mathrm{~mm}$ was cleaned for 15 minutes in an ultrasonic cleaner with a solution comprising of acetone, methyl-alcohol, and DI water, and dried with a nitrogen blower. The films were sputtered onto the glass substrates at room temperature. Before deposition, the target was cleaned by sputtering for about 10 minutes to minimize the contamination of the target during the opening of the chamber. The deposition parameters of fabricating single layer of Mo films are listed in Table 1. The thickness of films is kept at about $500 \mathrm{~nm}$ to avoid blurring the measurement of electrical characteristics. After the results of studying single layer film, the deposition conditions of the second films for a bilayer stack will be on one of the better condition of single layer film data.

Crystal structure of the films was examined and crystallized phases in films were identified by a thin film XRD (Rigaku D/ max-B) with monochromatic Cu K $\alpha$ radiation, and microstructural analyses of the top and cross-section of the films were conducted
Table 1. Sputtering parameters for depositing single layer of Mo thin films.

\begin{tabular}{llllllll}
\hline Power (W) & 200 & 250 & 300 & 350 & 400 & 450 & 500 \\
\hline Pressure (mTorr) & 2.5 & 5 & 10 & 15 & 20 & & \\
Ar flow (Sccm) & 30 & & & & & & \\
Thickness (nm) & 500 & & & & & & \\
Deposition time(min) & 14 & 10.9 & 8.1 & 7 & 6.1 & 5.3 & 5 \\
\hline
\end{tabular}

by a FESEM (field-emission scanning electron microscope, HITA$\mathrm{CHI}$ S-4700). The deposition rates of the films were calculated by thickness data measured from SEM results, and electrical resistivity of Mo films was measured using a 4-point probe method with KEITHLEY 2400. Adhesion to the substrate after deposition was tested by Scotch tape test method. Carrier mobility of the Mo films was investigated by a Hall-effect measurement system (ECOPIA HMS-3000 ver. 3.5). In addition, samples were scratched to a rectangle shape and adhesive tape stripes of the same length were glued on the scratched films and stripped with approximately equal amounts of force.

\section{Results and Discussion}

Figure 1 shows XRD patterns of the Mo films prepared at 10 mTorr and DC sputtering power, all films showed a typical bodycentered cubic (BCC) Mo structure (space group $\operatorname{Im} 3 \bar{m}$ ), with a major peak $\left(40.5^{\circ}\right)$ corresponding to an orientation along (1 10) direction. The intensities of the XRD peak indicated that the films grew with a preferred orientation along the (110) plane as increasing sputtering power, a typical feature of the Mo films deposited by sputtering processes at room temperature (Assmann et al. 2005). Stress of the deposited Mo films on glass is crucial for the application on CIGS cell. The residual stresses in the Mo sample determined by the Voigt fit for the XRD measurement are shown in Figure 2, which exhibits the effect of sputtering power condition on the Mo films stress. The compressive stress increases as the power increases from $300 \mathrm{~W}$ to $500 \mathrm{~W}$. The residual stress in films changes from tensile to compressive, which was dependent of voids in crystalline lattices and grain boundaries bombarded by the energetic ions (Thornton et al 1989).

Figure 3 shows top view SEM images of the Mo films prepared at a $10 \mathrm{mTorr}$ and the different working powers from $200 \mathrm{~W}$ to $500 \mathrm{~W}$. Grains with small pyramidal shape were observed in the sample with lower sputtering powers. With increasing the sputtering power, the grains turn to mackerel shape with larger size. The films deposited at higher powers display a larger packed grain microstructure with closed boundaries and less voids, because the Mo particles have a longer free path way and a higher kinetic energy during the deposition (Gordillo 1998). Table 2 presents the electrical resistivity and sheet resistance of the Mo films prepared at 10 mTorr with different DC sputtering power. The electrical resistivity and sheet resistance of the Mo film show same decreasing behavior with increasing sputtering power. Both of them are decreased as increasing the sputtering power, similar to the work by Li et al. (2011). Table 3 presents the resistivities and sheet resistance of Mo films prepared at $300 \mathrm{~W}$ and different working pressure. High working pressure in sputtering does not favor the electrical properties 


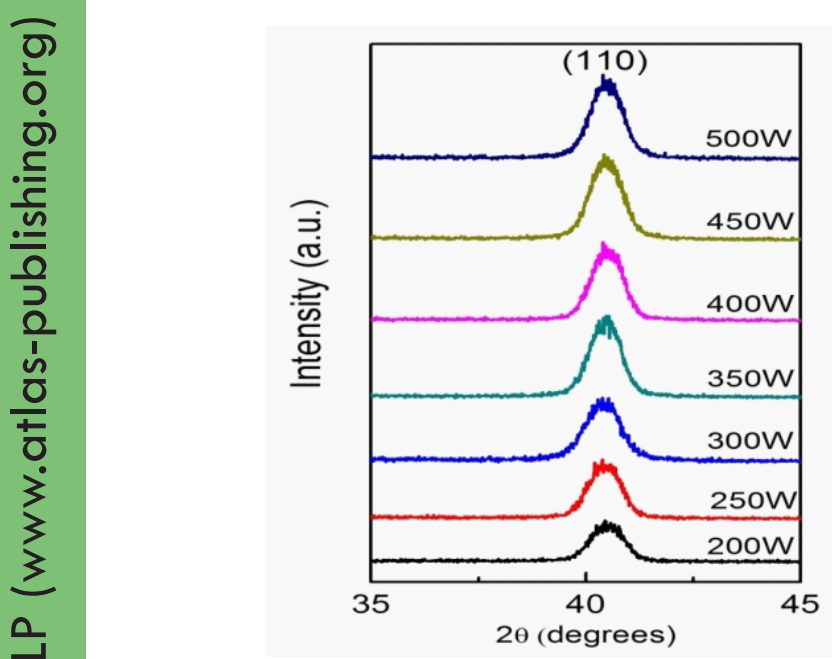

Figure 1. XRD patterns of characteristic (1 10$)$ peaks of Mo films prepared at $10 \mathrm{mTorr}$ and different DC sputtering powers.

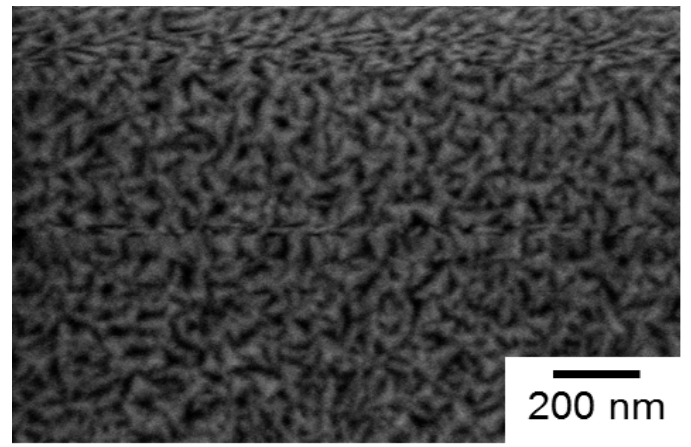

(a) $200 \mathrm{~W}$

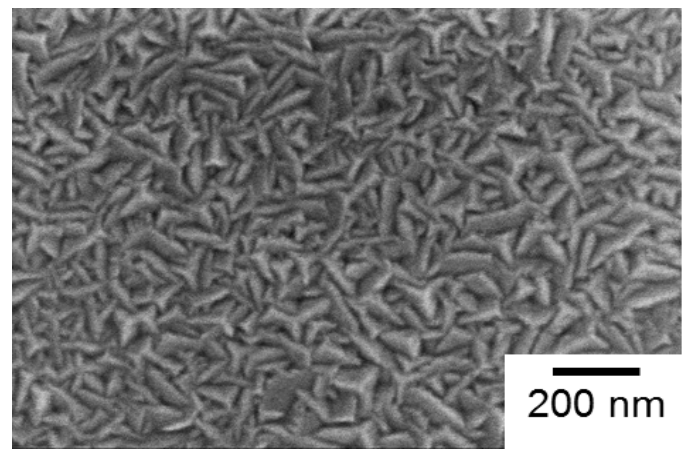

(c) $300 \mathrm{~W}$

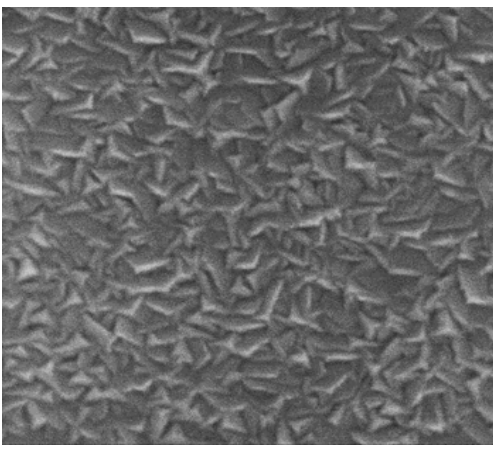

(e) $450 \mathrm{~W}$

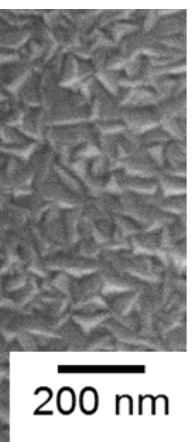

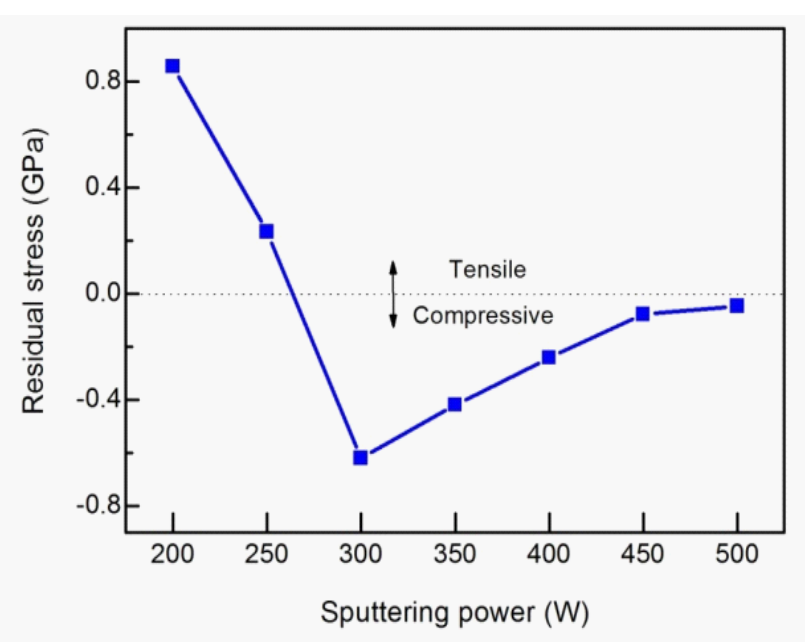

Figure 2. Residual stress vs. sputtering power of Mo thin films at 10 mTorr were determined by XRD.

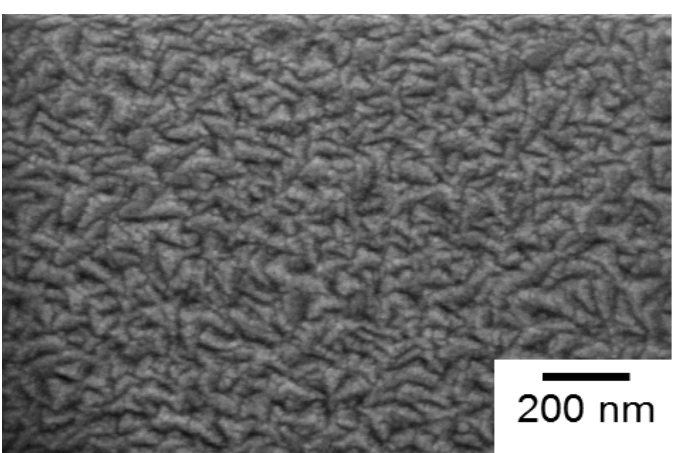

(b) $250 \mathrm{~W}$

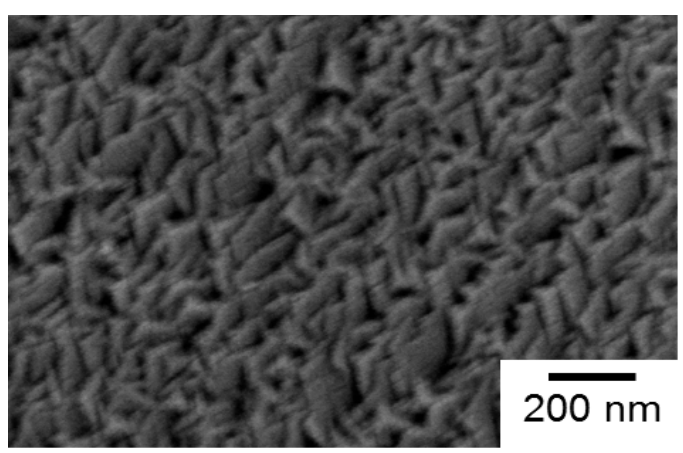

(d) $400 \mathrm{~W}$

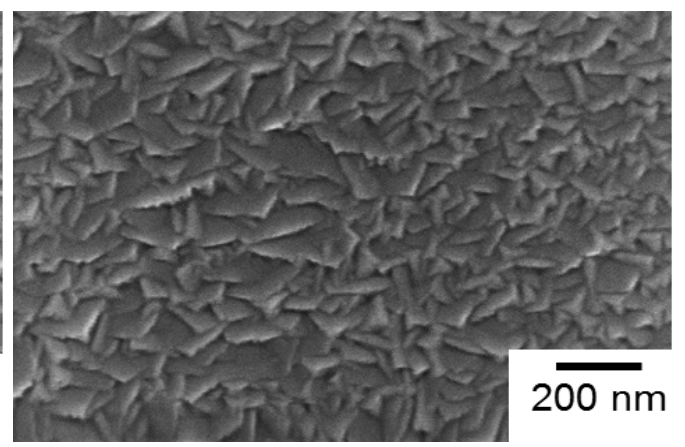

(f) $500 \mathrm{~W}$

Figure 3. Top surface SEM images of Mo films prepared at $10 \mathrm{mTorr}$ and different sputtering power. 
Table 2. Resistivities and sheet resistance of Mo films prepared at 10 mTorr and different sputtering power.

\begin{tabular}{ccc}
\hline Power $(\mathbf{W})$ & Resistivity $(\boldsymbol{\mu} \boldsymbol{\Omega} \cdot \mathbf{c m})$ & Sheet resistance $(\boldsymbol{\Omega} / \square)$ \\
\hline 200 & 78.09 & 1.698 \\
250 & 60.23 & 0.844 \\
300 & 49.77 & 0.775 \\
350 & 49.51 & 0.741 \\
400 & 38.95 & 0.415 \\
450 & 35.48 & 0.364 \\
500 & 31.35 & 0.296 \\
\hline
\end{tabular}

Table 3. Resistivities and sheet resistance of Mo films prepared at $300 \mathrm{~W}$ and different working pressure.

\begin{tabular}{ccc}
\hline Pressure (mTorr) & Resistivity $(\mu \Omega \cdot \mathrm{cm})$ & Sheet Resistance $(\Omega / \square)$ \\
\hline 2.5 & 16.93 & 0.32 \\
5 & 25.89 & 0.51 \\
10 & 31.03 & 0.62 \\
15 & 41.95 & 0.81 \\
20 & 92.28 & 1.85 \\
\hline
\end{tabular}

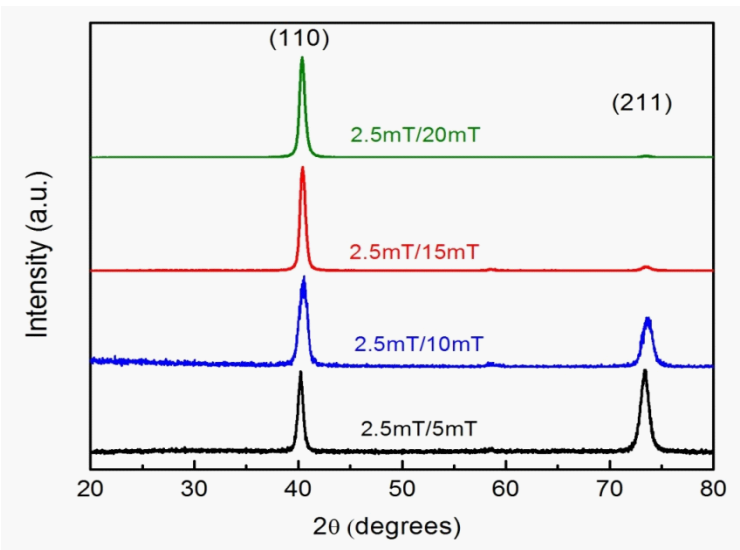

Figure 4. XRD patterns of of Mo films prepared at $300 \mathrm{~W}$ and different $D C$ working pressure.

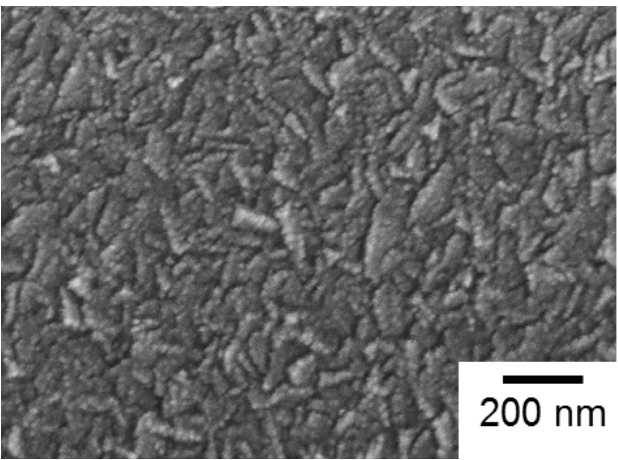

(a) 5 mTorr

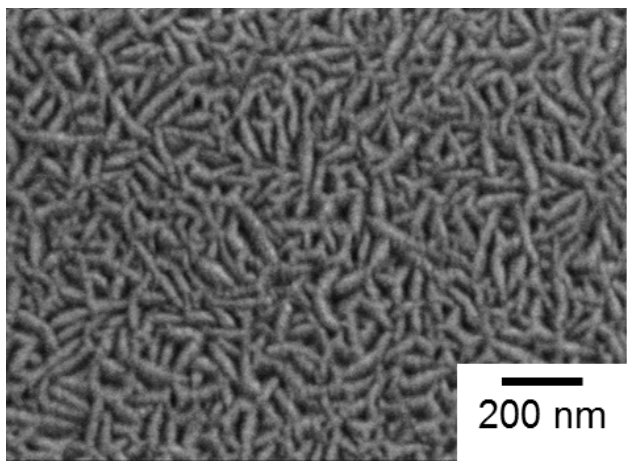

(a) 15 mTorr

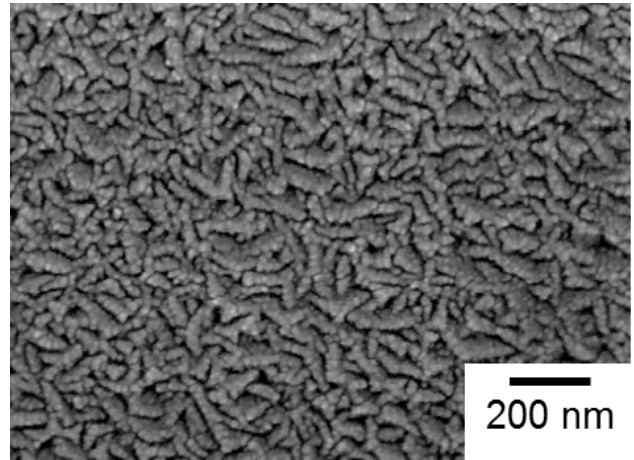

(b) 10 mTorr

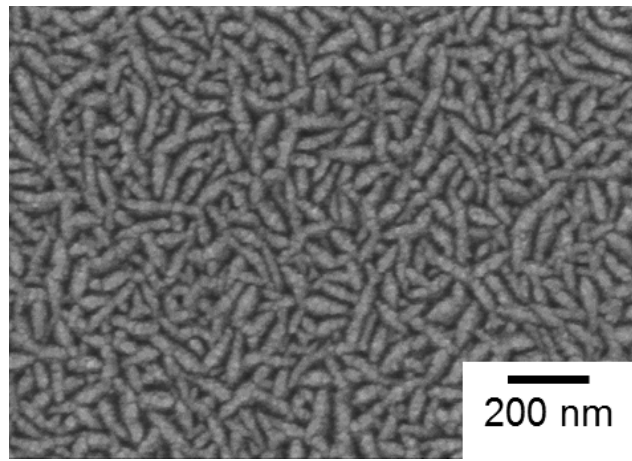

(b) 20 mTorr

Figure 5. Top surface SEM images of bilayer Mo films while top layer films prepared at $300 \mathrm{~W}$ and different working pressure. 
Table 4. Resistivities and sheet resistance of bilayer Mo films with the top layer films prepared at $300 \mathrm{~W}$ and different working pressure.

\begin{tabular}{ccc}
\hline (bottom/top) (mTorr) & Resistivity $(\mu \Omega \cdot \mathrm{cm})$ & Sheet resistance $(\Omega / \square)$ \\
\hline $2.5 / 5$ & 17.14 & 0.17 \\
$2.5 / 10$ & 20.84 & 0.19 \\
$2.5 / 15$ & 23.73 & 0.22 \\
$2.5 / 20$ & 24.65 & 0.23 \\
\hline
\end{tabular}

of the Mo films. As compared with Tables 2 and 3, the minimum resistivity of single layer Mo films deposited with $300 \mathrm{~W}$ and $2.5 \mathrm{mTorr}$ is about $17 \mu \Omega \cdot \mathrm{cm}$.

When the sputtering power rises, the atomic energy of ion bombardment of molybdenum deposited on the substrate increases. Mo film surface morphology, such as small pyramids with pore membrane structure, transform to larger dense triangular cone structure.

Owing to the poor adhesion of the low resistive Mo films on the SLG, the bilayer stack structure of Mo films is employed in the application of CIGS cell. The top layer of a bilayer Mo films $(500 \mathrm{~nm})$ is fixed at deposition conditions of $300 \mathrm{~W}$ and 2.5 mTorr for the lowest resistivity for minimizing ohmic contact issue of CIGS absorber films. The bottom layer of Mo thin films is fixed to $500 \mathrm{~nm}$ and deposited at $300 \mathrm{~W}$ and different working pressures. Figure 4 shows the XRD patterns of of Mo films prepared at $300 \mathrm{~W}$ and different DC working pressure. The intensity of (211) peaks are decreased with increasing the working pressure. Figure 5 shows the top surface SEM images of bilayer Mo films while top layer films prepared at $300 \mathrm{~W}$ and different working pressure. The shape of the grains seem to be different from the morpholorgy of single-layer Mo films. Long sharp columnar grains appear at higher working pressure. A higher working gas pressure in sputtering will change the quality of the top layer film (Moons e al. 1993). Table 4 shows the resistivities and sheet resistance of bilayer Mo films while top layer films prepared at $300 \mathrm{~W}$ and different working pressures. As compared with the Figure 5, less packing density of columnar grains will induce more scattering events for carrier motion.

Increasing the sputtering power of molybdenum thin films from $200 \mathrm{~W}$ to $500 \mathrm{~W}$ at $10 \mathrm{mTorr}$ yields a decrease in resistivity from $78.09 \mu \Omega \cdot \mathrm{cm}$ to $31.35 \mu \Omega \cdot \mathrm{cm}$, possibly because the residual stress changes from tensile to compressive stress. Likewise, films with the working pressure increased from $2.5 \mathrm{mTorr}$ to 20 mTorr at $300 \mathrm{~W}$ shows increased resistivity from $16.93 \mu \Omega \cdot \mathrm{cm}$ to $92.28 \mu \Omega \cdot \mathrm{cm}$ while the residual stress of Mo films is compressive stress, except for tensile stress observed at 2.5 mTorr.

\section{Conclusions}

The single layer and bilayer Mo films were successfully prepared using DC sputtering. The residual stress of the single layer films changed from tensile to compressive when the sputtering power is reduced. The lowest resistivity of single layer Mo film was about $17 \mu \Omega \cdot \mathrm{cm}$, which acted as a top contact layer of bilayer electrode. The resistivity of bilayer Mo films with bottom layer deposited at a sputtering power of $300 \mathrm{~W}$ and various working pressures showed the resistivity around 17-25 $\mu \Omega \cdot \mathrm{cm}$ that was lower than results by Wang et al. (2014). These results indicated that the bilayer Mo films prepared by the study could be used as back metal contacts in CIGS solar cells.

\section{Acknowledgements}

This work was financially supported by the Chung-Shan Institute of Science and Technology (CSIST) under the Contract No. CSIST-706-V102.

\section{References}

Assmann L, JC Bern`ede, A. Drici, C. Amory, E. Halgand, and M. Morsli (2005) Study of the Mo thin films and Mo/CIGS interface properties. Applied Surface Science 246: 159-166.

Dhere MNG (2007) Toward GW/year of CIGS production within the next decade. Solar Energy Materials \& Solar Cells 91: 1376-1382.

Dresselhaus S and IL Thomas (2001) Overview Alternative energy technologies. Nature 414: 332-337.

Gordillo G, M Grizalez, and LC Hernandez (1998) Structural and electrical properties of DC sputtered molybdenum films. Solar energy materials and solar cells 51:327-337.

Green MA, K. Emery, Y. Hishikawa, W. Warta, and E. D. Dunlop (2012) Solar cell efficiency tables (version 39). Prog. Photovolt: Res. 20: 12-20.

Hoffman RA, J. C. Lin, and J. P. Chambers (1991) The effect of ion bombardment on the microstructure and properties of molybdenum films. Thin Solid Films 206: 230-235.

Hsiao KJ, JD Liu, HH Hsieha and TS Jianga (2013) Electrical impact of MoSe2 on CIGS thin-film solar cells. Phys. Chem. Chem. Phys. 15: 18174-18178.

Huang PC, CH Huang, MY Lin, CY Chou, CY Hsu, and CG Kuo (2013) The Effect of Sputtering Parameters on the Film Properties of Molybdenum Back Contact for CIGS Solar Cells. International Journal of Photoenergy 2013: 390824 (8 pages).

Jackson P, D Hariskos, E Lotter, S Paetel, R Wuerz, R Menner, W Wischmann and MY Jeong, CW Kim, DW Park, SC Jung, J Lee, and HS Shim (2011) Field modulation in Na-incorporated $\mathrm{Cu}(\mathrm{ln}, \mathrm{Ga}) \mathrm{Se} 2$ (CIGS) polycrystalline films influenced by alloy-hardening and pairannihilation probabilities. Nanoscale Res Lett. 6: 581-586.

Jubault M, L Ribeaucourt, E Chassaing, $G$ Renou, D Lincot, and F Donsanti (2011) Optimization of molybdenum thin films for electrodeposited CIGS solar cells. Solar Energy Materials and Solar Cells 95: S26-S31.

Li ZH, ES Cho, SJ Kwon (2011) Molybdenum thin film deposited by inline DC magnetron sputtering as a back. Applied Surface Science 257: 9682-9688.

Moons E, T Engelhard, and D Cahen (1993) Ohmic contacts top-CulnSe2 crystals. Journal of Electronic Materials 22: 275-280.

Powalla (2011) New world record efficiency for Cu (In, Ga)Se2 thin $\square$ film solar cells beyond 20\%. Prog. Photovolt: Res. Appl. 19: 894897.

Singh UP and SP Patra (2010) Progress in Polycrystalline Thin-Film $\mathrm{Cu}(\mathrm{In}, \mathrm{Ga}) \mathrm{Se} 2$ Solar Cells. International Journal of Photoenergy 2010: 468147 (19 pages).

Thornton JA and DW Hoffman (1989) Stress-related effects in thin films. Thin solid films 171:5-8.

Wang SF, HC Yang, CF Liu, and HYY Bor (2014) Characteristics of 
Bilayer Molybdenum Films Deposited Using RF Sputtering for Back Contact of Thin Film Solar Cells. Advances in Materials Science and Engineering 2014, 531401 (6 pages).

Wu HM, SC Liang, YL Lin (2012) Structure and electrical properties of Mo back contact for $\mathrm{Cu}(\mathrm{In}, \mathrm{Ga}) \mathrm{Se} 2$ solar cells. Vacuum 86: $1916-$
1919.

Yoon JH, S Cho, WM Kimetal. (2011) Optical analysis of the microstructure of a Mo back contact for $\mathrm{Cu}(\mathrm{ln}, \mathrm{Ga}) \mathrm{Se} 2$ solar cells and its effects on Mo film properties and Na diffusivity. Solar Energy Materials and Solar Cells 95: 959-2964. 